Opinion Article

\title{
The Climate does not Change from Carbon
}

\section{Oleg Khalidullin*}

Academician of the Kazakh National University, Kazakhstan

*Address for Correspondence: Oleg Khalidullin, Academician of the Kazakh National University, Kazakhstan. Tel: +87770550099; Email: 7115215@mail.ru

Received: 16 August 2020; Accepted: 25 August 2020; Published: 27 August 2020

Citation of this article: Khalidullin $\mathrm{O}(2020)$ The Climate does not Change from Carbon. Rea Int J of Energy Environ Sci. 1(1): 011-012. DOI: 10.37179/rijees.000003.

Copyright: (C) 2020 Khalidullin O. This is an open access article distributed under the Creative Commons Attribution License, which permits unrestricted use, distribution, and reproduction in any medium, provided the original work is properly cited.

The climate is changing from the artificial evaporation that humanity has created. Artificial vapors differ from natural vapors in quality, volume, and speed. The water is for consumption only - for drinking. But we, not understanding her essence, made her a slave. Transformed into a working agent, a means of increasing comfort.

They began to use it as a liquid for washing everything and everyone, move it with pumps, heat and boil, cool, dissolve all chemical elements in it, fill in the fields, destroy its molecules in the air with engines, furnaces and compressors.

Almost everything used goes into the atmosphere, bypassing the biota, by unnatural vapors directly and from the sewage sump. Artificial evaporation destroyed the age-old process of sedimentation, which had been improving for millions of years. Different structure of water molecules of new volumes, rates of evaporation form a different mechanism. New quantities create new qualities.

The processes of concentration, movement, interaction with the atmosphere have changed - pressures, temperatures, moisture transfer have changed in new time parameters. Uncontrollable in terms of volume and time, precipitation is formed in other volumes, in a different capacity, and falls in other places. Therefore, floods occur in some places, droughts in others. Therefore, the level of the oceans rises - heavy clouds do not reach mountain and polar glaciers.

A hypothesis requires proof. Proof of a conjecture leads to discovery. The discovery should lead to a new concept. The basis of the concept is a change in the natural chain of transformation of the structure of water when it moves through the soil, under the soil, dissolving minerals and supplying them to natural inhabitants. These functions are embedded in wild forests and unspoiled areas. But we, with our desire for comfort, have taken away from nature more than $75 \%$ of the earth's area, and by 2050 this figure may exceed $90 \%$; - https://vyvoz-org.turbopages.org/s/vyvoz.org/blog/opustynivaniezemel/

We flooded all these lands with reservoirs, plowed up:

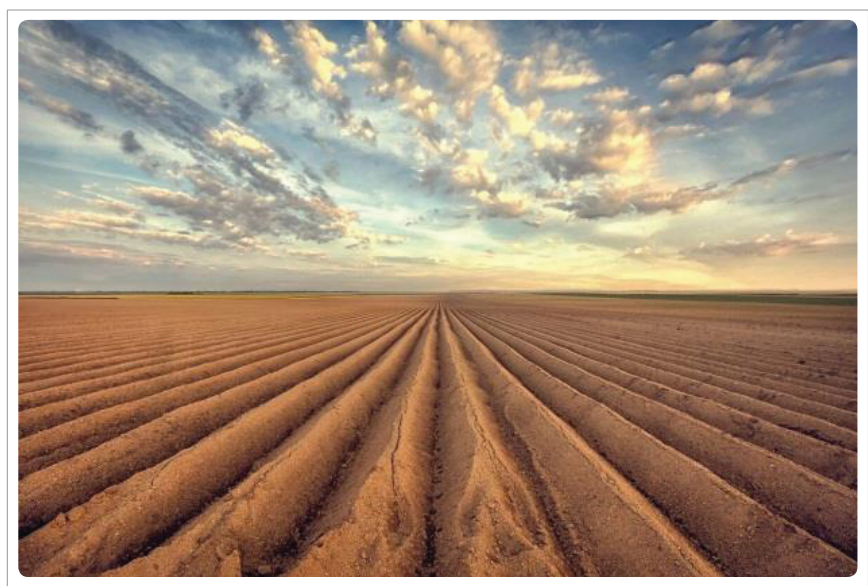

covered with garbage and ore landfills, structures, and roads. Throughout this area, there was vegetation and living creatures that processed water into vapors and fumes, which have special qualities. These qualities constitute a crucial part of the Hypothesis. The structure of vapors from biota has boundless sets of various types and properties: these are breath vapors, transpiration of plants, phytoncides, pheromones, odors, billions of types of excretions in the form of urine, blood, sweat from every living creature and species.

If living creatures have disappeared on $75 \%$ of the degraded land, the water is forced to return to the atmosphere without fulfilling its natural obligations. The quality of these fumes is completely different. What came with the rain came back, the cycle of transformations was 
reduced. The water cycle has lost its essence. New volumes of vapors new to nature have shown new properties. The volumes, speed and time spent by restless water in the clouds have changed. The eternal process of sedimentation and the graphs of precipitation broke down.

It is still possible to save life on the planet. Not by appeals and wishes, but to fundamentally restructure your attitude to water, reduce your needs for water, make this a strategy of every state, every person. Nature urgently needs to return its natural process of water circulation.

All worries, work, movement on green technologies, reduction of carbon dioxide emissions, alternative energy, preservation of biodiversity, protection, and restoration of nature - all this is combined under a single action.

There are such opportunities if you use the experience of developed countries, use a lot of inventions in this direction. It is known that in the Scandinavian countries and Japan there are no longer landfills; in Israel, plant products are grown with minimal water consumption. Houses with vertical and roof gardening are known. Known inventions that allow generating electricity without reservoirs in rivers. There are ways to save water on airplanes and trains.

All such measures should be developed and applied when using water in all technologies in all cities and countries. Only returning it to nature, millions of years of accumulated water cycle, can reduce natural disasters and stop climate change. It is necessary to fulfill such tasks by the whole world, every enterprise, every country, every person.

More details at https://juniperpublishers.com/jojwb/JOJWB. MS.ID.555551.php.

https://biomedres.us/pdfs/BJSTR.MS.ID.003658.pdf,

https://medcraveonline.com/IJH/IJH-04-00233.pdf

https://e.mail.ru/attach/15910975130481038937/0\%3B1/?folderid $=0$ \&x-email $=7115215 \% 40$ mail.ru

https://actascientific.com/ASMI/ASMI-03-0529.php

I invite you to cooperation. A little effort and we can become the authors of the discovery. 